DOI: $10.30842 /$ ielcp230690152438

\author{
A. Мутон (Centre National de la Recherche Scientifique) \\ И. С. Якубович (Институт востоковедения РАН) \\ ПРОЛЕПТИЧЕСКАЯ КОНСТРУКЦИЯ \\ В ЛУВИЙСКОМ ЯЗЫКЕ
}

Лувийский язык относится к анатолийской группе, таким образом находясь в близком родстве с хеттским и еще более близком родстве с ликийским языком. Для пролептических конструкций в лувийских ритуальных заклинаниях характерны катафорические местоимения, кореферентные актантам в постглагольной позиции внутри той же клаузы. Целью настоящей статьи является описание данной конструкции с привлечением сравнительно-исторической, формальносинтаксической и прагматической аргументации. За вводным Разделом 1 следует Раздел 2, посвященный внешне противоречащим друг другу попыткам анализа клауз с местоименной репризой в различных анатолийских языках на основе выноса влево и выноса вправо. В Разделе 3 мы постарались разделить проблемы местоименной репризы и эволюции порядка слов в лувийском языке, показав, что на первый из этих процессов накладываются дополнительные ограничения. В ключевом Разделе 4 мы привели аргументацию в поддержку сосуществования выноса влево и выноса вправо в истории лувийского синтаксиса при доминирующем характере выноса влево. Завершающий Раздел 5 посвящен обсуждению типов актуального членения, которые могли передаваться лувийскими клаузами с начальной позицией предиката. Общий вывод работы состоит в том, что вынос влево и выноса вправо, каждый со своими сравнительными параллелями и функциональными коррелятами, сочетаются с отдельным, но общим для них явлением местоименной репризы и таким образом совместно отвечают за появление пролептической конструкции в лувийском языке.

Ключевые слова: хеттский язык, лувийский язык, ликийский язык, вынос влево, вынос вправо, местоименная реприза.

A. Mouton (Centre National de la Recherche Scientifique), I. S. Yakubovich (Institute of Oriental Studies, RAS)

\title{
Proleptic Construction in the Luwian Language
}

Luwian is an Anatolian language, closely related to Hittite and even more so to Lycian. The proleptic construction in Luwian ritual incantations is characterized by a cataphoric clitic pronoun, which co-references an argument placed in post-verbal position within the same clause. The goal of this paper is elucidating the syntax of this construction with the help of comparative-historical, formal, and pragmatic approaches. After the introductory Section 1, Section 2 addresses the seemingly contradictory 
explanations of this phenomenon in various Anatolian languages offered thus far, which allegedly involved either fronting or right dislocation of the cross-referenced constituents, but usually not both. In Section 3, we attempt to disengage the problems of clitic doubling and word order permutation in Luwian, arguing that the former involves additional constraints. Section 4 is crucial for the argument of this paper, in that it contains the evidence that both fronting and left dislocation affected the Luwian word order, but the former was probably more important. In the concluding Section 5, we explore the pragmatic configurations that were likely responsible for the rise of Luwian verb-initial clauses. We come to a general conclusion that the separate phenomena of fronting and right dislocation were both amplified by a yet separate phenomenon of clitic doubling, which triggered the grammaticisation of proleptic construction in Luwian.

Keywords: Hittite, Luwian, Lycian, fronting, right dislocation, clitic doubling.

\section{1. Постановка проблемы}

Темой настоящей статьи является описание конструкции с глаголом в начальной или срединной позиции и катафорической местоименной клитикой, дублирующей один из постглагольных актантов ${ }^{1}$. Ради краткости мы будем именовать такую конструкцию пролептической. Лувийский язык принадлежит к анатолийской группе индоевропейской (индоанатолийской) языковой семьи, и, таким образом, является близким родственником хеттского языка. Еще ближе, однако, с генетической точки зрения к нему относятся языки так называемой лувической подгруппы, среди которых лучше всего засвидетельствован и дешифрован ликийский язык (точнее, ликийский А, в противоположность ликийскому Б, иногда именуемому милийским). Собственно лувийские тексты засвидетельствованы в двух различных системах письма, а именно в местной иероглифической письменности и в анатолийской адаптации месопотамской клинописи. Практически все известные лувийские клинописные тексты представляют собой вкрапления внутри хеттских сочи-

${ }^{1}$ Данное исследование выполнено в рамках международного проекта "Luwili: Luwian Religious Discourse between Anatolia and Syria", финансируемого грантами французкого Agence nationale de la recherche (ANR-17-FRAL-0007-01) и немецкого Deutsche Forschungsgemeinschaft (YA 472/2-1) под руководством соответственно А. Мутон и И. С. Якубовича. В рамках настоящей статьи Мутон взяла на себя филологическую обработку клинописного лувийского материала, а Якубович - его лингвистический анализ. Мы благодарны Н. Н. Казанскому и Крэгу Мелчерту за многочисленные замечания по теме статьи. 
нений. Основным материалом росписи текстов для данной статьи являются клинописные лувийские заклинания, отражающие традиции Пуриянни и Куватталлы (СТН 758-763).

Лувийскую пролептическую конструкцию можно проиллюстрировать аннотированными клаузами (1-3), где катафорические клитики выделены полужирным шрифтом. Как можно видеть из этих примеров, позиция глагола определяется не по отношению к границе клаузы, а по отношению к позиции актантов. Это, в частности, позволяет распространить описание на сложные предикаты, как в примере (1), и глаголы с отрицанием, как в примере (3). Наиболее частотным в клаузах с пролептической конструкцией является порядок слов с предикативными группами в начальной позиции, который мы будем в дальнейшем именовать $\mathrm{V}_{1}$. Что касается местоименной репризы, то для ее выражения используются субъектные и объектные местоименные клитики, неизменно выступающие в ваккернагелевской позиции, то есть после первого ударного слова. При этом в непереходных клаузах дублируется подлежащее, как в примерах (1-2), а в переходных - прямое дополнение, как в примере (3) ${ }^{2}$. Косвенные дополнения местоименными клитиками не дублируются ${ }^{3}$.

(1) KUB 35.54 iii 34-36 (CTH 758), cp. Starke 1985: 69

la-a-ú-na-i-mi-ša-aš

lahunaimmis $=\mathbf{a s}$

мыть-NOM.SG.C=он.NOM.C

a-aš-du

astu

[ta-]ru-uš-ša

ti-ya-am-mi-išs

[DINGIR $^{\text {MEŠ }}$-e]n-zi massaninzi

tiyammis

земля.NOM.C

бог.POSS-NOM.PL.C

[hu-]u-uh-hur-ša-
huhhursantinzi

x.NOM.PL

\footnotetext{
${ }^{2}$ Единственным вероятным исключением здесь является пример (28). Хотя клитику /=as/ в данном примере можно рассматривать как репризу подлежащего (ед.ч; м.р) или дополнения (мн.ч; м.р), первая интерпретация является более вероятной по семантическим соображениям (cp. Yakubovich 2012: 332-333). Вероятно, реприза подлежащего в данном примере связана с тем, что дополнение в винительном падеже является не прямым, а косвенным (см. перевод в Разделе 4).

${ }^{3}$ Данная формулировка в некоторой степени упрощает проблему, поскольку многие косвенные дополнения дублируются в лувийском языке при помощи частицы $/=(\mathrm{t}) \mathrm{ta} /$. Следует, однако, отметить, что, во-первых /=(t)ta/ не является местоимением, а во-вторых употребление данной частицы не зависит от относительной позиции сказуемого и косвенного дополнения. В любом случае, синтаксис частицы $/=(\mathrm{t}) \mathrm{ta} /$ должен стать темой отдельного исследования.
} 
GUNNI[-ti-iš]

hassanittis

алтарь.NOM.SG

'Да будут они омыты, [дре]весина, земля, $x$.-ы [бог]ов (и) алта(рь)'

(2) KBo 29.6 obv. 23'-24' (CTH 762), cp. Starke 1985: 129

a-ú-i-du-pa-aš-ta

ma[-a]l-ha-aš<-ša-aš>-ši-iš

awidu $=\mathrm{ba}=\mathbf{a s}=\mathrm{ta}$

malhassassis

прийти.3SG.IMPV=a=oн.NOM.C=PTCL ритуал.POSS-NOM.SG.C

$\begin{array}{lll}\text { EN-aš } & \mathrm{h}[\mathrm{a} \text {-ra-at-na-a-ti] } & \text { wa-aš-ku-li-im-ma-a[-ti] } \\ \text { niyas } & \text { haratnadi } & \text { waskulimmadi } \\ \text { господин.NOM.SG } & \text { преступление.ABL } & \text { грех.ABL }\end{array}$

'Да выйдет он, заказчик ритуала, из-под (власти) п[реступления] (и) грех[а]'.

(3) KUB 32.9+ obv. 7-8 (CTH 760), cp. Starke 1985: 129: 87

$\begin{array}{lll}\text { ni-i-ša-an } & \text { ha-pí-ti } & \text { ma-a[1-ha-aš-ša-aš-ši-in] } \\ \text { niš=an } & \text { habidi } & \text { malhassassin } \\ \text { PROHIB=он.ACC.C } & \text { вязать.3SG.PRS } & \text { ритуал.POSS-ACC.SG.C }\end{array}$

EN-an $\mathrm{a}[\mathrm{d}-\mathrm{du}-\mathrm{wa}$-li-iš

EME-iš] ad-du-wa-li-iš

niyan attuwalis

господин.ACC.SG злой.NOM.SG.C lalis attuwalis язык.NOM.C злой.NOM.SG.C

i-išs[-ša-ri-iš]

issaris

рука.NOM.C

'Да не скуют его, заказчика рит[уала], з[лой язык] (и) злая дл[ань]'.

Выбор ритуальных традиций Пуриянни и Куватталлы в качестве основы для анализа обусловлен не только их общими диалектными характеристиками, а также их вхождением в группу взаимосвязанных ритуалов, но и тем фактом, что лувийская пролептическая конструкция засвидетельствована как таковая лишь внутри данного корпуса. Приведенные выше клаузы внешне контрастируют с примерами (4-6), взятыми соответственно из позднелувийского текста в иероглифической передаче, ритуала Царпии, и заклинания, отражающего традицию североанатолийского города Тауриса. Во всех примерах

\footnotetext{
4 Здесь и ниже лувийские клитики единственного числа переводятся на русский во множественном числе. Это связано с особенностями правил согласования: в лувийском языке как катафорические, так и анафорические клитики часто согласуются по числу лишь с одним из элементов сочинительной конструкции, тогда как в русском согласование происходит со всей группой.
} 
этой группы $\mathrm{V}_{1}$ не сопровождается местоименной репризой. Следует также оговориться, что клаузы с $\mathrm{V}_{1}$ являются значительно менее частотными в текстах этой группы, чем в традициях Пуриянни и Куватталлы. Нормой для глагола здесь является позиция на конце клаузы ${ }^{5}$.

(4) KARATEPE 1 (Hu.) § 7, cp. Hawkins 2000, I: 49

("MANUS<">)su-wá/í-ha-ha-wá/í

suwahha=ha=wa

|pa-há+ra/i-wa/i-ní-zi (URBS)

наполнить.1SG.PRT=и=PTCL

pahrawanninzi

|(<“>HORREUM")ka-ru-na-zi

пахровский.ACC.PL.C

karunanzi

амбар.ACC.PL.C

'И я наполнил амбары (города) Пахра'.

(5) KUB 9.31 ii 26-27 (CTH 757), cp. Starke 1985: 53

$\begin{array}{lll}\text { a-az-za-aš-ta-an } & \text { UDU-in-za } & \mathrm{GU}_{4} \text {-in-za } \\ \text { aztan } & \text { hawinz(a) } & \text { wawinz(a) } \\ \text { есть.2PL.IMPV } & \text { овца.ACC.PL } & \text { корова.ACC.PL }\end{array}$

'Ешь овец (и) коров!'

(6) KUB 35.88 iii 11' (CTH 765), cp. Starke 1985: 227

$\begin{array}{llll}\begin{array}{l}\text { ú-pa-at-ta=pa=wa=du } \\ \text { uppatta=ba=wa=du }\end{array} & \text { ša-ar-ri-ya-ni-in } & \text { 2-šu } & \text { 9-u[n-za ...] } \\ \text { достать.3SG.PRT=a=PTCL=oн.DAT } & \text { sarriyanin } & \text { twisu } & \text { nunza } \\ \text { скребок.ACC.SG } & \text { дважды } & \text { девять }\end{array}$

'Она достала ему дважды дев[ять] скребниц'.

Синхронное описание пролептической конструкции в лувийском языке частично зависит от выбранной синтаксической парадигмы. Синтаксические теории можно классифицировать как деривационные (трансформационные) и недеривационные (калькуляционные). Деривационные теории, наиболее известными из которых являются модели Хомского и его школы, допускают синтаксические трансформации, в частности, выносы влево и выносы вправо. Недеривационные теории калькулируют поверхностный синтаксис на основании сопоставления различных параметров, в первую очередь, предикативноактантной, коммуникативной и интонационной структуры предложения. Что касается исторического синтаксиса, здесь

\footnotetext{
${ }^{5}$ Относительно более частое употребление клауз с глаголом в начальной позиции в позднелувийских надписях KARATEPE и ÇİNEKÖY вероятно обусловлено влиянием их финикийских исходных версий, ср. Yakubovich 2015: 44-45.
} 
доминирует деривационное описание. В частности, если исходить из предположения, что модель $\mathrm{S}(\mathrm{O}) \mathrm{V} / \mathrm{O}(\mathrm{S}) \mathrm{V}$ являлась стандартной для предка лувийского языка на определенном историческом этапе, то развитие отклонений от данной модели должно описываться как тенденция к выносу предиката влево или к выносу актантов вправо. Поскольку различие в порядке слов в разных группах лувийских текстов должно иметь историческое объяснение, в настоящей работе мы будем в основном придерживаться трансформационной терминологии. В то же время, коммуникативная структура предложения будет привлекаться для объяснения синтаксических трансформаций.

\section{2. История изучения вопроса}

На предшествующие исследования лувийской пролептической конструкции сильно повлияла хеттология, что само по себе не удивительно, учитывая наличие сходной конструкции в хеттском языке и тот факт, что большинство специалистов в области лувийского языка также являются и хеттологами. Между тем, доминантой хеттологических исследований является гипотеза о калькированном характере пролептической конструкции. В частности, указывается на ее частотный и систематический характер в переводах с хаттского языка на хеттский (Rizza 2007) и в хетто-хурритской билингве (напр. Sideltsev 2002: 167-171). Также отмечается, что употребление местоименной репризы лишь в определенной части хеттской версии ритуала Мастигги против семейных ссор отражает редакционный процесс и, таким образом, свидетельствует о восприятии данной лувийской конструкции в качестве сомнительного элемента профессионального жаргона (Rieken 2011: 500-502). В работе Melchert 2015 местоименная реприза прямо увязывается со стилем переводных текстов (translationese). Хотя наличие пролептической конструкции в хеттских непереводных текстах и отстаивается в статье Sideltsev 2011, относительно небольшое число примеров, приводимых автором в поддержку своего тезиса, свидетельствует, как минимум, о ее периферийном характере в данном корпусе.

Совсем иная картина вырисовывается при обращении к лувийским заклинаниям в традициях Пуриянни и Куватталлы. Нет никаких оснований говорить об их переводном характере: само их сохранение внутри хеттских ритуальных текстов свидетельствует о нежелании писцов переводить лувийские 
заклинания, что могло бы привести к утрате их иллокутивной силы (Yakubovich 2019: 289). Между тем, конструкции с $\mathrm{V}_{1}$ являются достаточно частотными внутри нашего корпуса, составляя 20-30\% от всех лувийских клауз в текстах СТН 758763 , и в большинстве случаев они сопровождаются местоименной репризой. Хотя гипотеза об их относительно большей частотности в ритуальном жаргоне и является правомерной, исполнители ритуалов, первоначально ориентированных на лувийскую языковую среду, явно использовали модели своего родного языка.

Тем не менее, исследователи лувийского синтаксиса эксплицитно или имплицитно исходили из гипотезы о формальной идентичности пролептических конструкций в хеттском и лувийском языках. В частности, Рицца, связывая лувийскую конструкцию с употреблением пространных именных групп с однородными членами в соответствующих клаузах (Rizza 2007: 67), рассматривает данную корреляцию вместе с аналогичной корреляцией в хеттских переводных текстах. Лувийская конструкция интерпретируется как результат выноса вправо в работах Мелчерта (Melchert 2003: 201, Melchert 2006: 296), сходная интерпретация также принимается для хеттской конструкции в работе Melchert 2015. В данном вопросе с Мелчертом солидаризуется и Сидельцев, cp. работы Sideltsev 2011 для хеттского и Sideltsev 2012 для лувийского ${ }^{6}$. Наконец, Рикен, указывая на непоследовательность употребления местоименной репризы в ритуальной традиции Мастигги, прямо сравнивает ее со сходным феноменом в лувийском (Rieken 2011: 502-503, сн. 10).

\footnotetext{
${ }^{6}$ При этом следует подчеркнуть коренное отличие выводов Мелчерта и Сидельцева относительно социолингвистического статуса соответствующих оборотов. Мелчерт отказывал обеим конструкциям в языковой реальности, классифицируя, как уже упоминалось выше, хеттские клаузы как пример translationese, и анализируя лувийские заклинания как особые поэтические фигуры речи, не характерные для разговорного языка (Melchert 2006). Напротив, Сидельцев отстаивает реально-языковой характер лувийской пролептической конструкции в единственной известной нам работе, целиком посвященной данной теме (Sideltsev 2012), и, как было указано выше, также стремится доказать, что пролептическая конструкция является частью хеттской грамматики. Таким образом, авторы настоящей статьи скорее солидаризуются с социолингвистическими выводами Мелчерта в отношении хеттского языка и Сидельцева - в отношении лувийского.
} 
В настоящей статье мы хотели бы обратить внимание на конструкцию, которая пока, кажется, не привлекалась в качестве сравнительного материала при обсуждении местоименной репризы в лувийском. Речь пойдет от ликийских назализованных претеритах, характерных для переходных глаголов в позиции после частиц $m(e)=$ and $s(e)=$, которые контрастируют с претеритами без назализации, образуемыми от тех же глаголов в других контекстах. Важным коррелятом данного распределения является тенденция к порядку слов VS в клаузах с назализованным претеритом («правило Имберта-Гарретта»). Обе эти особенности претеритов с назализацией можно проиллюстрировать примером (7), противопоставленным примеру (8), где назализованные и неназализованные окончания выделены полужирным шрифтом. Хотя последняя конструкция и является менее частотной в ликийском языке, с морфосинтаксической точки зрения она явно проще, и поэтому естественно рассматривать ее в качестве отправной точки при деривации.

(7) TL 103.1

ebẽñnẽ :

xupã :

$\mathrm{m}=\mathrm{ene}$ :

вот.это.ACC.SG.M

могила.ACC.SG PTCL=он.ACC.SG.M

prñnawatẽ :

tebursseli

строить.3SG.PRT. T.NOM.SG

‘Тебурсели построил эту гробницу'.

(8) TL 40a.1

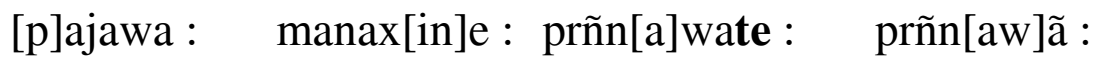

P.NOM.SG M.NOM.SG построил.3SG.PRT строение.ACC.SG

ebẽñnẽ

вот.это.ACC.SG.M

'Паява Манахине (титул или эпитет) возвел это строение'.

Согласно убедительной гипотезе, изложенной в недавней статье Адьего, "at a certain point in the prehistory of Lycian ... verb-"fronting" implied a clitic doubling" (Adiego 2015: 26). На этой стадии клауза (7) имела бы форму *prñnawat $(e)=\tilde{e}$ tebursseli ebẽ̃̃ne хира̃, то есть то, что стало впоследствии маркером назализованного претерита, должно было функционировать на этом этапе как объектная местоименная клитика в ожидаемой ваккернагелевской позиции. Нетрудно увидеть, что синтаксис реконструированной ликийской клаузы напоминает синтаксис лувийской пролептической конструкции с переход- 
ным глаголом, в частности, в примере $(3)^{7}$. Таким образом, данную конструкцию можно восстанавливать для пралувического, или, возможно, для лувического диалектного ареала, включающего в себя ликийский язык и некоторые лувийские диалекты. Добавление демаркационных частиц $s(e)=$ and $m(e)=$, а также вынос топика влево в позицию перед $m(e)=$, как в примере (7), следует считать инновациями ликийского языка (Adiego 2015: 27-28). При этом данный синтаксический процесс сопровождается местоименной репризой, см. вторичную местоименную клитику =ene, добавленную к частице $m(e)=$ в том же примере (7). Уместно отметить, что более ранняя реконструкция ликийских назализованных претеритов (Garrett 1991, 1994), отличаясь важными деталями от сценария, предложенного Адьего, также оперирует последовательностью выносов влево в истории ликийского языка.

Таким образом, наблюдается противоречие между точкой зрения хеттологов, последовательно оперирующих выносом актантов вправо в хеттском и лувийском языках, и гипотезой о выносе предиката и актантов влево, доминирующей среди исследователей ликийского языка. Учитывая более близкое родство между лувийским и ликийским языками по сравнению с лувийским и хеттским, предшествующие хеттоцентрические интерпретации, как минимум, заслуживают дополнительной проверки. В настоящей работе мы постараемся осуществить пересмотр материала средствами корпусного анализа. Прежде чем приступить к данной задаче, следует, однако, прояснить соотношение между двумя элементами лувийской пролептической конструкции - базовым порядком слов и местоименной репризой.

\section{3. Местоименная реприза}

Материал, приведенный в первых двух разделах, говорит в пользу связи местоименной репризы и синтаксической инверсии в лувийском и ликийском языках. Клаузы с $\mathrm{V}_{1}$, как правило, используют или не используют катафорические мес-

\footnotetext{
7 Лувийская субъектная клитика /=as/, в отличие от /=an/, не могла иметь когнатов в ликийском языке, способных повлиять на форму претерита, поскольку конечное $*_{-s}$ выпадает в истории ликийского языка, а гипотетическая клитика *=e должна была поглотиться глагольными окончаниями с исходом на гласную и исчезнуть, как это и произошло с ней в других синтаксических позициях.
} 
тоимения, а клаузы с частицами $m(e)=$ и $s(e)=$ демонстрируют обязательную назализацию в определенных грамматических формах переходных глаголов. Тем не менее, с исторической точки зрения изменение базового порядка слов и употребление катафорических местоимений следует рассматривать как два отдельных явления. Одним из аргументов в пользу такого подхода является лувийская конструкция с частицей zawi 'вот', используемая при демонстрации новых предметов ритуала. Местоименная реприза является здесь факультативной: она отсутствует в примерах (9-10), но присутствует в примерах $(11-12)$.

(9) KUB 35.54 ii 31' (CTH 758), cf. Starke 1985: 67

$\begin{array}{llll}\text { za-a-ú-i } & \text { zi-ya-ar } & \text { NUMUN.HI.A-na? } & \text { [p]u-u-na-a-ta } \\ \text { zawi } & \text { ziyar } & \text { warwalana } & \text { punada } \\ \text { вот } & \text { лежать.3SG.PRS } & \text { семя.NOM.PL } & \text { весь.NOM.PL }\end{array}$

'Вот лежат всякие семена'.

(10) KUB 35.54 ii 41' (CTH 758), cf. Starke 1985: 67

$\begin{array}{lll}\text { za-a-ú-i=pa } & \text { t[ap-paš-š] } & \text { ' } \text { ti’-ya-am-mi-iš } \\ \text { zawi=ba } & \text { tappassa } & \text { tiyammis } \\ \text { вот=a } & \text { небо.NOM.SG } & \text { земля.NOM.SG }\end{array}$

'А вот н[еб]о (и) земля'.

(11) KUB 35.54 ii 8' (CTH 758), cf. Starke 1985: 66

$\begin{array}{ll}\text { za-a-ú-i-ya-aš } & \text { ta-lu-up-pí[-і̌̌] } \\ \text { zawi=as } & \text { taluppis } \\ \text { вот=он.NOM.C } & \text { комо[к].NOM.SG }\end{array}$

'Вот он, комо[к] (теста)'.

(12) KUB 32.9+ ii 3' (CTH 760), cf. Starke 1985: 87

\begin{tabular}{|c|c|c|}
\hline 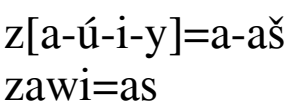 & $\begin{array}{l}\text { ú-i-ši-ta } \\
\text { wisida }\end{array}$ & $\begin{array}{l}\text { ha-la-a[-li-iš }] \\
\text { halalis }\end{array}$ \\
\hline от=он.NOM.C & явиться.3SG.PRT & чистый.NOM.SG.C \\
\hline
\end{tabular}

'В[от] он появился, чис[тый] комок (теста)'.

С формальной точки зрения zawi-клаузы относятся к типам конструкций, где ожидалась бы местоименная реприза, поскольку предикат (там, где он имеется) предшествует в них субъекту. Чем же обусловлена наблюдаемая вариативность? Можно предложить гипотезу, согласно которой появление 
катафорической местоименной клитики связано со степенью прагматической освоенности (assumed familiarity) дублируемого референта ${ }^{8}$. Напротив, комок теста многократно применяется в очистительных обрядах в ритуальных традициях Пуриянни и Куватталлы, В частности, «семена» (скорее всего, модели соответствующих предметов) и модели земли и неба являются артефактами, используемыми по одному разу в ритуале Пуриянни (СТН 758), поэтому на момент их демонстрации соответствующие референты можно считать прагматически неосвоенными (unused). Напротив, комок теста многократно применяется в очистительных обрядах ритуальных традиций Пуриянни и Куватталлы, поэтому его можно считать прагматически доступным (accessive) ${ }^{9}$. В частности приведенный ниже контекст из ритуальной традиции Куватталлы предвосхищает демонстрацию данного предмета ритуала:

(13) KUB 35.58' ii 5'-6' (CTH 761), cf. Starke 1985: 164

ha-la-li-ša ${ }^{(\mathrm{e} .)}$-an

halalis $=$ an ta-lu-up-pí-iš [ha-la-la-an-nu-wa-at-tu? $]$ чистый.NOM.SG.C=он.ACC.C taluppis halalanuwattu $\begin{array}{lll}\text { [pa-] }{ }^{\top} \mathrm{a}^{\top}-\mathrm{aš} & \text { ha-la-li-ǐ̌ } & \text { a-aš-du } \\ \mathrm{pa}=\mathrm{as} & \text { halalis } & \text { astu }\end{array}$ затем=он.NOM.C $\quad$ чистый.NOM.SG.C быть.3SG.IMPV '[Да очистит $\left.{ }^{?}\right]$ его чистый комок (теста), [и] да будет он чист!'

8 Мы опираемся здесь на иерархию прагматической освоенности (Lambrecht 1994: 109), суммирующую результаты монографии Prince 1981. Основными параметрами данной иерархии является степень когнитивной доступности (известное / неизвестное) и степень дискурсивной активации (неожиданное / ожидаемое). Следует подчеркнуть отличия между освоенностью референта и его ролью в коммуникативной структуре предложения, которая, разумеется, идентична в примерах (9-12).

9 Прагматические корреляты местоименной репризы не являются типологической диковинкой: см. например обсуждение таких коррелятов в македонском языке в работе (Kalluli, Tasmowski 2008: 10-13). Внутри балканского языкового союза прагматические параметры также играют роль в описании местоименной репризы в албанском и румынском языках (ibid: 9). Связь местоименной репризы с прагматическими характеристиками референта в балканских языках отмечается уже в монографии Лопашов 1978. Уникальность референта выдвигалась в качестве условия назализации ликийских претеритов в работе Goldstein 2014 (ср. обсуждение истории данного ликийского феномена в Разделе 2). 
Другое вероятное ограничение на местоименную репризу имеет синтаксический характер. Пример (14) контрастирует с KUB 29.3+ iii 17' $m$ [a-am]-ma-al-wa-ya-an EN SÍSKUR-iš ad-duwa-li-in EME-in 'Co[к]рушает его заказчик ритуала, злой язык' (ср. (27) ниже). В примере (14) аккузативное дополнение прямо следует за глаголом в начальной позиции, при отсутствии ожидаемой ваккернагелевской клитики. Напротив, в примере (27) между ними вставляется подлежащее, а клитическое местоимение ожидаемым образом дублирует дополнение. Полный анализ лувийского корпуса подтверждает вывод об отсутствии местоименной репризы в тех случаях, когда дублирующее местоимение должно было бы оказаться в позиции непосредственно перед дублируемым дополнением. Интересно, что данный запрет не распространяется на подлежащее, ср. примеры (11), а также (28) и (30) ниже ${ }^{10}$.

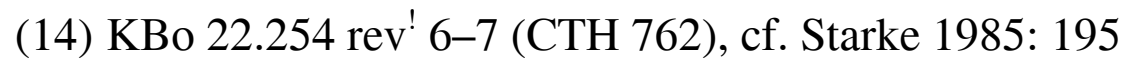

ma-am-ma-lu-wa-i [a]d-du-wa-li-in-<<zi>> Š [U-in]

mammalwai attuwalin issarin

ломать.3SG.PRS злой.ACC.SG.C рука.ACC.SG

[ad-du-w]a-li-in EME-e[n]

attuwalin lalin

злой.ACC.SG.C язык.ACC.SG

'Сокрушает (он) злую д[лань] (и) [зл]ой язык'.

Изложенные гипотезы позволяют представить в новом свете контраст между клаузами (1-3) и (4-6), для которых исходно предполагалось диалектное распределение. Выясняется, что данные примеры также оказываются распределены по характеру прагматической освоенности аргументов: в примерах (1-3) дублируемый референт является «старым», тогда как в группе (4-6) все референты, которые могли бы вызывать местоименную репризу по своим грамматическим характеристикам, являются «новыми». Кроме того, во всех клаузах группы (4-6) прямое дополнение непосрественно следует за ваккернагелевской позицией.

Данные факты допускают двоякую интерпретацию. С одной стороны, можно было бы предполагать, что приведенные выше правила блокировки местоименной репризы действовали во

\footnotetext{
${ }^{10}$ Последние два примера, впрочем, менее доказательны, поскольку местоименная клитика и подлежащее отделены здесь пространственной клитикой /=(t)ta/.
} 
всех диалектах лувийского языка, то есть диалектный статус контраста между примерами (1-3) и (4-6) является иллюзорным. С другой стороны, по крайней мере, для позднелувийской надписи из Каратепе можно отметить отсутствие катафорических местоимений также и в конструкциях с освоенными референтами и при отсутствии смежности ваккернагелевской позиции и позиции прямого дополнения (KARATEPE § 37, § 72). Поэтому блокировка местоименной репризы носила здесь более распространенный характер, или же местоименная реприза вообще отсутствовала в позднелувийском языке. Напротив, для предка ликийского языка нет необходимости реконструировать правила блокировки, по крайней мере в интерпретации Adiego 2015. Не исключено, что сложные правила блокировки катафорических местоимений в определенных лувических диалектах как раз и привели ситуации к аналогическому выравниванию в ту или иную сторону в других диалектах.

Возвращаясь к нашему корпусу (СТН 758-763), можно отметить, что кроме описанных выше сучаев здесь обнаруживаются также и другие клаузы с инновативным порядком слов, отклоняющиеся от классической пролептической конструкции. Например, если в предложении уже имеются местоименные клитики в анафорической функции, местоименная реприза не имеет места (см. ниже примеры 18,20 ). В этом случае отсутствие клитики, дублирующей подлежащее, является прямым следствием запрета на сосуществование субъектной и объектной клитики в одной и той же клаузе в древних анатолийских языках. К списку формальных исключений можно добавить также клаузы, обсуждаемые в работе Rieken, Yakubovich (в печати), где местоименная реприза реконструируется на морфологическом уровне, но не проявляется в поверхностной репрезентации перед частицей /=tta/ по причинам морфонологического характера. Примерами подобного явления в настоящей работе являются $(19,26,36)$. Относительно сходного феномена в лувийских иероглифических текстах см. Rieken 2008: 640-641.

Менее тривиальным исключением является пример (15), где в роли дейктического и одновременно катафорического местоимения выступает zas 'этот'. Мы сталкиваемся здесь с двойной нерегулярностью: во-первых, местоимение здесь тоническое, а не клитическое, во-вторых, оно дублирует субъект, а не объект, как ожидалось бы в переходной клаузе. Похоже, что тут 
отражена разговорная конструкция, где все дейктические элементы вынесены в начальную позицию, пусть и за счет потери смежности составляющих, что мы и попытались отобразить в русском переводе примера (15). Однако коль скоро местоимение zas воспринималось также и как катафора, отсутствие объектной катафорической клитики оказывается вполне регулярным: правила лувийского языка не допускают двойную местоименную репризу.

(15) KUB 35.43+ ii 9-11 (CTH 760), cf. Starke 1985: 144

[na-nu-um-p]a za-aš nanum $=$ pa zaš теперь=же этот.NOM.SG.C

ha-a-ú-i-iš hawis [ša-hu-i-t]a-an-ta-an sahwidantan овца.NOM.C

\section{pa-ra-ad-du} parattu нести.3SG.IMPV a-ar-ra-az-za<-aš $>$ arrazzas белый? $. N O M . S G . C$

'[Теперь ж]е, вот эта пусть унесет белая овца [пу]ты (и) удары!'

Другим примером отсутствия ожидаемой местоименной репризы прямого дополнения является клауза (16). Данное предложение, которое Э. Рикен (Rieken 2011) использовала для демонстрации вариативности местоименной репризы в лувийском языке, следует рассматривать в контексте сходных заклинаний, сопровождающих обряд омовения, где источники ритуальной нечистоты обозначены формами не аккузатива, а аблатива. Ср. фрагменты KUB 27.26 r. col. 6'-7' il-ha-ti-ti [ma-alha-ǎ́s $\check{s} a-a \check{s}-\check{s} i-i \check{s}$ EN-ǎ́] ta-pa-ru-wa-ti [ta-ta-ri-ya-am-na-ti hi-ruú-ta-ti] и KUB 35.62 1. col. 2'-3' [e-l]i-el-ha-a-i-t[i ma-al-ha-aš-šaa ̌̌šsi-iš EN-aš ta-pa-ru-wa-ti ta-ta-ri-ya-am-na-ti hi-r]u-ú-ta-ti, для которых можно предложить перевод 'Да отмоется заказчик ритуала от напасти (манипуляции), проклятия (и лживой)

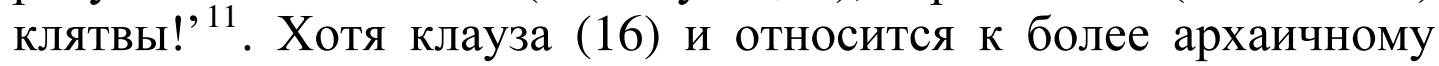
тексту, чем приведенные выше параллели, в обсуждаемой синтаксической конструкции их можно рассматривать в сопоставлении друг с другом как свидетельство неустойчивости пациенса, которая могла проявляться как через неустойчивость падежной маркировки так и через отсутствие дублирующей местоименной клитики.

11 Относительно гипотетической интерпретации лув. tabaru- как 'manipulation', см. Mouton, Yakubovich 2019: 212-213, прим. 6. 
(16) KUB 32.9+ rev. 30'-31' (CTH 760), cf. Starke 1985: 90

\begin{tabular}{|c|c|c|}
\hline $\begin{array}{l}\text { i-li-il-ha-a-i=ti } \\
\text { ililhai=di } \\
\text { мыть.3SG.PRS=REFL.3SG }\end{array}$ & $\begin{array}{l}\text { m[a-al-]ha-aš-ša-aš-ši-iš } \\
\text { malhassassis } \\
\text { ритуал.POSS-NOM.SG.C }\end{array}$ & $\begin{array}{l}\text { [EN-aš } \\
\text { niyas } \\
\text { господин.NOM.SG }\end{array}$ \\
\hline $\begin{array}{l}\text { pa-ru } \\
\text { aru } \\
\text { ипуляция.ACC.SG }\end{array}$ & $\begin{array}{l}\text { da-a-ta[-ri-ya-am-ma-an] } \\
\text { tadariyamman } \\
\text { проклятие.ACC.SG }\end{array}$ & $\begin{array}{l}\text { hi-ru-ú-un } \\
\text { hirun } \\
\text { клятва.ACC.SG }\end{array}$ \\
\hline
\end{tabular}

'Да смоет с себя [заказчик] р[ит]уала напасть (манипуляцию), про[клятие], (лживую) клятву ... !'

Несмотря на указанные выше исключения, материал лувийских заклинаний, принадлежащих к традициям Пуриянни и Куватталлы (СТН 758-763), подтверждает гипотезу о том, что пролептические конструкции являются основным типом лувийских клауз с инновативным порядком слов (то есть, с глаголом в начальной или срединной позиции). В этом можно убедиться на основании более полной росписи материала, приведенной ниже. Вместе с тем, местоименная реприза представляет собой самостоятельное явление и поэтому ее наличие или отсутствие не может стать решающим фактором при выборе того или иного способа описания вариативности порядка слов в лувийском языке.

\section{4. Вынос влево или вынос вправо?}

Вопрос об исторических причинах синтаксической вариативности в лувийских заклинаниях логически разделяется на две части. С одной стороны, можно пытаться определить механизм, отвечающий за повышение продуктивности такого порядка слов на основании формальных параметров. С другой стороны, для содержательного объяснения данного процесса необходимо дать функциональное описание конструкции или конструкций, обобщивших инновативную синтаксическую модель. В данном разделе мы сосредоточимся на формальной стороне проблемы, отложив функциональную интерпретацию на завершающий раздел статьи.

С формальной точки зрения, минимизация передвижений синтаксических составляющих внутри клаузы отвечает критерию экономии. Следовательно необходимо предпочесть один вынос влево двум выносам вправо и наоборот. В качестве точки отсчета, мы исходим из праанатолийского базового порядка слов $\mathrm{S}(\mathrm{O}) \mathrm{V} / \mathrm{O}(\mathrm{S}) \mathrm{V}$, непосредственно отраженного в хеттских 
текстах и соответствующего общепринятой в современной индоевропеистике реконструкции конечной позиции глагола. Мы также постулируем предглагольную позицию косвенных дополнений в праязыке. Напротив, положение подлежащего относительно дополнений не является типологически значимым параметром для анатолийских языков, а определяется прагматической структурой конкретной клаузы. В частности, подсчеты Марии Молиной по различным подкорпусам хеттских текстов показывают в среднем соотношение 3:1 между моделями SOV и OSV (Molina 2019: 77-78). Преобладание порядка слов SOV обусловлено языковой фреквенталией, согласно которой подлежащее обычно совпадает с темой (topic).

Таким образом, для предположения о сдвиге предиката влево достаточной является конфигурация с предикатом, за которым следуют как минимум два актанта и которому не предшествует ни один актант. В том случае, если справа и слева от предиката находится по одному актанту, следует скорее постулировать вынос актанта вправо, чем исходить из труднообъяснимого движения предиката в срединную позицию.

В том случае, если в клаузе есть лишь один актант, и он следует за предикатом, гипотезы о выносе влево и выносе вправо являются равноправными. Разумеется, подобная методология ведет к гипотетическим выводам в каждом конкретном случае, которые могут быть уточнены в результате функционального анализа. Тем не менее, при наличии достаточного количества примеров она, как минимум, может статистически обосновать предположение о наличии того или иного механизма в истории языка.

Ниже собраны примеры, иллюстрирующие феномен сдвига предиката влево. Для этого была проведена полная роспись лувийских текстов группы (СТН 758-763), однако отобраны лишь те случаи, где заполнение лакун является надежным с точки зрения авторов статьи, и отсеяны почти или полностью идентичные предложения. Ради сокращения объема текста здесь и ниже примеры приводятся в упрощенной транслитерации, без транскрипции, морфологической аннотации и ссылок на вторичную литературу; группа предиката и группы актантов разделяются знаком $\|$. Клитические местоимения, как катафорические, так и анафорические, переводятся на русский язык, но не учитываются при сегментации, поскольку их синтаксическая позиция автоматически определяется законом Ваккернагеля. 
(17) KUB 35.54 ii 49'-iii 5 (CTH 758)

[š] āndu=wa=ta $\|$ parnantinzi [h]ūmmatiš haššanittiš huwahhuršantinzi tiyammiš tarušantiš $\|$ ad[duwalza utarša] hallišša parattan[za] puwatilza [n]anuntarriš[a] irhūwašša pa[r]ittaruwāššsa] ulantalliyan huitw[aliyan]

'Да извергнут их части дома, \| (то есть) [у]часток, алтарь, huwahhuršant-, фундамент (досл. земля) (и) каркас (досл. древесина), \| зл[ую речь], хворь, скве[рну], прошлую (и) настоящую, внутреннюю (и) внешнюю, (исходящую) от мертвых (и) жив[ых]!'

(18) KUB 35.54 iii 9-11 (CTH 758)

$\mathrm{a}=\mathrm{ta}=\mathrm{tta}$ pari patzadu $\|$ MÁŠ́.GAL-iš $\|$ māuwāti pārtāti mannakunati SI-nati

'Да унесет еe \| козел \| на четырех конечностях, морде (и) рогах!'

(19) KUB 35.55 obv. 8'-10' (CTH 758)

[ka]rašdu(w)=at=ta ā[ppa \| EN SISKUR \| ādd]uwalza utarša [hallišša parattanza]

'Да [от]сечет их оп[ять $\|$ заказчик ритуала, \| зл]ую речь, [хворь (и) скверну]!'

(20) KUB 32.10+ obv' 7'-8' (760)

[āhš $]$ andu(w)=ata $\|$ DINGIR $^{\text {MEŠ }}$-zi $\|$ dū[pa]niyati ša[huidantalliyati uit]antalliyati

'Да [осво]бодят их $\|$ боги $\|$ от к[а]ры, парали[зующей (и) по]ражающей!'

(21) KUB 32.10+ obv. 9'-10' (760)

[lālad]du=pa=aš $\|$ malhaššaššiš EN-aš $\| d[$ ārušša mī̌sanza hāšša halhalzanin warann]āhiša iunahiša lalpin [kuwannanin maššanallin KASKAL-an]

'Да [забер]ет их (себе) || заказчик ритуала, $\|$ те[ло, плоть, кости, суставы, красно]речие, ловкость, ресницы, [брови, (и) дорогу к богам]!'.

(22=3) KUB 32.9+ obv. 7-10 (CTH 760)

nīš=an hapiti \| ma[lhaššaššin] EN-an \| a[dduwališ EME-iš] adduwališ išs[šariš taparuwaššiš dātariyamnaššiš EME-iš] hirutaššiš EME-i[క̌ MU.KAM-iš adduwališ ITU.KAM-aš adduwališ $]$ wašpantaš[š]inzi ē[rhuwanzi mayaššiš EME-iš]

'Да не скуют его \| заказчика ри[туала], \| з[лой язык], злая дл[ань, язык напастий (и) проклятий], язык (лживых) клятв, [злой год, злой месяц], со[держимое] саванов, [злословие толпы]!' 
(23=15) KUB 32.9+ rev. 30'-31' (CTH 760)

ililhāi=ti \| m[al]haššaššiš [EN-aš $\|$ t]aparu dāta[riyamman] hirūn māya[ک̌ši]n EME-in

'Смывает с себя \| [заказчик] р[ит]уала \| напасть, про[клятие], лживую клятву, злословие то[лп]ы!'.

(24) KUB 32.9+ rev. 31'-34' (CTH 760)

"pa[=as halal]iš ǎšdu \| ma[lhaššaššiš EN-aš] $\|$ māššananza parran adduwalati EM[E-ti ad]duwalati $\overline{1} \breve{s}$ [arati] taparuwaššanzati dātariyam[našša]nzati hirutašša[nzati] māyaššanzati EME-ti

'И да будет [он чис]т \| [заказчик] ри[туала], \| перед богами от злого язык[а, зл]ой дл[ани], (языка) напастей, про[кля]тий и (лживых) кл[ятв], злословия толпы!'.

(25=14) KUB 35.43+ ii 9-11 (CTH 760)

[nanum=p]a zaš paraddu $\|$ ārrazza<šs $>$ hāuīš $\|$ [šahuit]antan uitattan '[Теперь ж]е, эта пусть унесет \| белая овца || [пу]ты (и) удары!'

(26) KBo 29.3+ ii 7-10 (CTH 761)

ānta $=\mathrm{pa}=\mathrm{at}=\mathrm{ta} \quad$ arlanuwatta $\|$ SÍSKUR-aššanza $<\mathrm{n}>\quad$ EN-ya \| huîtwalahi<ta>ti ānnarummahi<-ta>ti MU.KAM.HI.A GÍD.DA EGIR.U $_{4}-M I^{\text {HI.A }}$-ti DINGIR $^{\text {MES̆ }}$-aššazati waššarahitati huitummanahitati

'Заменил же (он) их $\|$ для заказчика ритуала $\|$ жизнью, мужеством, долгими годами, будущими днями, благосклонностью (и) жизненной силой (исходящей) от богов' .

(27) KUB 29.3+ iii 12'-14' (CTH 761)

ma[m]malway=an $\|$ EN SÍSKUR-iš $\|$ adduwalin EME-in tātariyammanaššin hīrutaššin āššiwantattanaššin māiyaššin EME-in 'Сок[р]ушает их \|| заказчик ритуала, \| злой язык напастей, проклятия, лживой клятвы, нищеты, злословия толпы' .

(28) KUB 35.71+ ii 6-9 (CTH 760)

awidu(w)=a[š=ta] \| malhaššašš[iš EN-aš $\left.\|{ }^{\mathrm{U}}\right]^{\mathrm{RU}}$ Ninuwawannaššati ${ }^{\mathrm{D}} I S ̌ T A R$-aššānza[ti ${ }^{\mathrm{B}}$ Hiš]uwiyaššāzati hattaštarra[ti]

'Да выйдет он, $\|$ [заказчик] ритуа[ла], $\|$ из (состояния) ужаса от богини Иштар из Ниневии (и) [бога Хес]уэ!'

(29) KUB 35.11 ii 8'-11' (CTH 762?)

niš=pa=aš āhhaša[mmiš || SÍSKUR-iš EN-aš $\|$ dārušša] mišanza hašša $\mathrm{h}$ [alhalzanin uwarannāhiša] iunāhiša la[lpin kuwannanin]

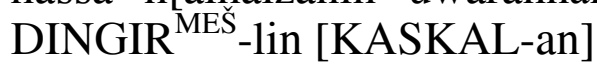

'И да не будет он поки[нут, || заказчик ритуала, \| (в отношении) тела] плоти, костей, су[ставов, силы], ловкости ре[сниц, бровей] (и) дороги к богам!'

(30) KBo 29.6 obv. 19’ (CTH 762) 
awidu(w)=ašs=ta \| malhaššašš[i]š EN-aš $\|$ haratnā[ti waškulimmāti] 'Да выйдет он, \| заказчик ритуала, \| из-под (власти) преступлен[ия и греха]!'

Приведенному выше материалу можно противопоставить небольшую группу примеров, которые говорят в пользу феномена выноса актантов вправо. Сразу же отметим, что все выносимые вправо словосочетания в примерах (31-33) состоят из трех или более словоформ. Это хорошо согласуется с наблюдениями монографии Rizza 2007 о влиянии сложности именной группы на ее синтаксическую позицию в языках Древней Анатолии, а в более общем плане - с так называемым «четвертым законом Бехагеля», согласно которому более длинная составляющая обычно располагается в предложении после более короткой. Напротив, если принять объяснение двойного сдвига вправо для клауз (17-30), пришлось бы допустить, что выноситься могут и такие элементы как 'боги', 'заказчик ритуала', 'белая овца' и 'козел',

KUB 35.54 iii 6-8 (CTH 758)

a=ta āppa zaštanza DINGIR ${ }^{\mathrm{MES}}$-anza parran $\|$ niš $<$ auiti $\|$ immarašša ${ }^{\mathrm{D}} \mathrm{IM}$-aššanza hallišša

'И назад к этим богам она \| пусть не <придет>, \| хворь степного бога грома!'

(32) KBo 29.3+ ii 26 (CTH 761)

a=an tiyammaššiš ${ }^{D}$ UTU-za $\|$ darawiddu \| tatariyammanaššin hirutaššin EN-an

'Земная богиня солнца его \| пусть выдаст, \| господина проклятия (и лживой) клятвы!'

(33) KUB 32.8+ iii 11'-14' (СTH 761)

harmāhati=ti(y)=an=ta \| tappānin \| lātta \| zanda dūpaimin iššarin zanda dūpaimin EME-in

'Их у себя с головы \| (как) волосок $\|$ он снял, \| разящую длань (и) разящий язык’.

Иную по своему характеру группу примеров, потенциально говорящих в пользу возможности выноса актантов вправо, составляют конструкции со структурной особенностью, известной в генеративной лингвистике как Right Node Raising. Если

\footnotetext{
12 При этом следует отметить, что термин 'заказчик ритуала' характерен прежде всего для писцового жаргона Хаттусы, тогда как при исполнении ритуала их заказчика обычно называли по имени. Это следует из указания $\breve{S} U M-\check{S} U$ halzāi 'она называет его по имени', часто добавляемого к описанию ритуалов (Görke 2010: 126-127, 277-278).
} 
исходить из ее трансформационной интерпретации, идентичные и кореферентные актанты параллельных клауз выносятся вправо, во внешнюю позицию по отношению к группам соответствующих клауз. Прототипическими примерами предложений с Right Node Raising в нашем корпусе являются (34-35). Напротив, пример (36) носит проблемный характер, поскольку здесь в постглагольной позиции оказывается не только группа прямого дополнения, но группа подлежащего. Если реконструкция данного текста является правильной, возможно говорить не об объединении двух клауз посредством вынесения их общего актанта на правую периферию, а о вынесении влево сериализованного предиката 'расплющит (и) отделит'. Заметим, что в примерах данной группы на правой периферии также последовательно оказываются более громоздкие составляющие ${ }^{13}$.

(34) KUB 32.8+ iii 26'-29': (CTH 759)

tāin=ti(y)=aš $\|$ āyaru $\|$ mal $<\mathrm{l}>\mathrm{i}=\mathrm{ti}(\mathrm{y})=\mathrm{a}<\breve{\mathrm{s}}>\|$ āyaru $\| \mathrm{za}[\mathrm{nda}]$ dūpaimmiš išša[rišs] zanda dūpaim[miš EME-iš]

'Маслом они || пусть станут, || медом они \| пусть станут, \| р[а]зящая дла[нь] (и) разящ[ий язык]!'

(35) KBo 29.3+ ii 21-24 (CTH 761)

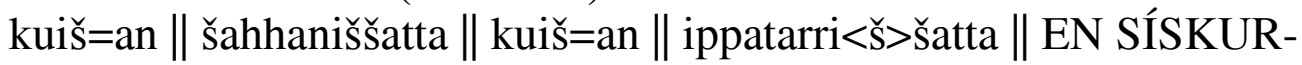
aššin ALAM-ša mīšanza hašša halhalzanin uwarannahiša iunahiša lalpin kuwannanin maššanalin KASKAL-an

'Кто их \| арестовал, || кто их || конфисковал - || тело, плоть, кости, суставы, красноречие, ловкость, ресницы, брови, дорогу к богам заказчика ритуала ...'

(36) KUB 35.54+ ii 11'-16' (CTH 758)

$\mathrm{a}=\mathrm{at}=\mathrm{ta}$ talkudu a[=at=ta karašdu] \| EN SÍSKUR āppa \| ảdd[uwalza] utarša EN SÍSKUR DINGIR ${ }^{\mathrm{MEŠ}}$-za [parran] imrašša DIM-aššanza [hallišša]

'Пусть расплющит их (и) [отсечет] их $\|$ заказчик ритуала опять, \| з[лую] речь [перед] богами заказчика ритуала (и) [хворь] степного бога грома!'

Подводя итоги данного раздела, можно констатировать, что случаи, когда лувийские конструкции с инновативным порядком слов удобно описывать как результат выноса влево и

${ }^{13}$ Ср.: '[В]ыносы синтаксически тяжелых и[менных] г[рупп] достаточно четко отличимы от выносов легких и[менных] г[рупп] в лувийском, чтобы составлять отдельную таксономическую категорию' (Sideltsev 2012: 773). 
выноса вправо, соотносятся приблизительно как 2:1. При этом примеры на вынос вправо уже получили удовлетворительное объяснение, тогда как причины выноса лувийской предикативной группы влево пока остаются без обсуждения. Как вынос влево, так и вынос вправо обычно сопровождаются местоименной репризой, хотя в первом случае она носит менее последовательный характер.

\section{5. Прагматическая интерпретация}

Очевидной особенностью материала, собранного в предыдущем разделе, является преобладание модальных форм предиката, присутствующих в 14 из 19 примеров. Поскольку лувийский корпус СТН 758-763 состоит из заклинаний, большое количество модальных предложений не вызывает удивления. Тем не менее, было бы неверным заключить, что лувийские заклинания состоят в основном из модальных клауз. В качестве контрольного отрывка лувийского текста, содержащего около 20 последовательных клауз с глаголом в индикативе, можно привести KUB 35.24+ obv. 5'-23'.

Другой особенностью предыдущего раздела, на этот раз прямо связанная с характером выборки материала, является отсутствие форм с глаголом в конечной позиции. При этом, в 14 из 19 клауз предикат находится в начальной позиции, то есть слева от всех актантов. Напротив, в контрольном «индикативном» отрывке KUB 35.24+ obv. 5'-23' все лувийские глаголы, кроме последних трех, находятся в конце клаузы. Последние три глагола, расположенные в начале клаузы (KUB 35.24+ obv. 19'-23') получили интерпретацию как императивные формы в более позднем варианте того же заклинания (KUB 35.43+ iii $\left.24^{\prime}-32^{\prime}\right)$ !

Но, пожалуй, наиболее наглядной иллюстрацией склонности лувийских императивных клауз к порядку слов $\mathrm{V}_{1}$ являются случаи хиазмов с морфосинтаксическим распределением (37-38). Частично эти примеры уже цитировались как (36) и (30). В примерах, приведенных ниже, контрастирующие однокоренные глагольные формы выделены полужирным шрифтом. Легко видеть, что причастные формы находятся на конце, а формы императива - в начале соответствующих клауз ${ }^{14}$.

\footnotetext{
14 Это не единственные примеры хиазма в лувийских заклинаниях ср.
} Melchert 2006: 297. Хиазм как фигура речи известен также и в родст- 
(37) KUB 35.54 ii 8'-13' (CTH 758)

zāwi=(y)aš taluppi[ $\check{s}$ a=aš=ta] kuramati hartat[i karšammiš $]$ kuluštanati tal[kummiš] a=at=ta talkudu $\mathbf{k}$ [araššuwadu zāš] EN SÍSKUR āppa ādd[uwalza] utarša

'Вот он, комо[к (теста), он отделен] разрезанием и помолом, распл[ющен] скалкой ${ }^{15}$. Пусть расплющит и от[делит] ее [этот] заказчик ритуала снова, зл[ую] речь!'

(38) KUB 29.6(+) i 22'-24 (CTH 762)

zaš $=$ pa $=$ tta kuwatin zammitatiš ${ }^{\mathrm{NA} 4}$ harrāti $[\ldots]$ awimmiš awidu $=\mathrm{pa}=\mathrm{aš}=$ ta malhaš<-šaš $>$ šiš EN-aš h[aratnāti] waškulimmā[ti] 'И как эта мука вышла из-под жернова [...], пусть выйдет он, заказчик ритуала, из-под (власти) п[реступления] (и) грех[а]!'

Корреляция между пролептической конструкцией с глаголом в начальной позиции и модальными предложениями (Götteranrufungen) уже отмечалась в отношении хеттских ритуальных традиций Туннавии и Мастигги (Rieken 2011: 500-502). В той же работе делается вывод о том, что синтаксические особенности данных предложений, в частности, характер распределения местоименной репризы, указывающий на редакционную правку, свидетельствует об их переводном характере. Как для традиции Туннавии, так и для традиции Мастигги, существуют независимые основания предполагать перевод или адаптацию заклинаний с лувийского (для последней традиции, cp. Yakubovich 2010: 33-36, 278-279). Роспись, произведенная в настоящей статье, указывает на сходный тип распределения пролептической конструкции в лувийских заклинаниях и их вероятных переводах на хеттский. Это, с одной стороны ведет к дальнейшему подтверждению выводов Рикен относительно редакционной истории традиций Туннавии и Мастигги, а с другой стороны указывает на то, что корреляция между пролептической конструкцией и модальными предложениями не ограничивалась какой-либо одной традицией, а была характерна для лувийского языка в целом или его определенного диалекта.

венном ликийском Б (милийском) языке, ср. Shevoroshkin 2012, однако там не обнаруживается его связь с модальными предложениями. ${ }^{15}$ Перевод существительного kulustann(i)- как 'скалка' является предположительным. Известно лишь, что это деревянный предмет, использовавшийся для сильного физического воздействия (ср. причастие (расплющен') и игравший важную роль при обработке зерна или муки. 
Кроме того, можно констатировать, что лувийский язык не одинок в своей тенденции к порядку слов $\mathrm{VS}(\mathrm{O})$ / $\mathrm{VO}(\mathrm{S})$ в клаузах с глаголом в императиве. В частности, та же тенденция характерна для ряда романских и западногерманских языков: анализ соответствующих данных в генеративной парадигме предлагается в работе Wratil 2010. Начальную позицию глагола в императивных клаузах можно также наблюдать на примере идиоматических конструкций русского языка, например: 'Храни тебя Господь!', 'Пошел он к черту!' или 'Да здравствует солнце, да скроется тьма!'. Подобные типологические параллели не обладают сами по себе объяснительной силой, однако они позволяют надеяться, что лувийская пролептическая конструкция не является чем-то уникальным и доступна для обычного анализа в терминах коммуникативной структуры (актуального членения).

Разумеется, не для всех лувийских контекстов можно предложить убедительную коммуникативную интерпретацию, как в силу их фрагментарного характера, так и в силу объективной сложности анализа информационной структуры текста на мертвом языке, то есть без доступа к интонационному контуру. Однако как раз в случае хиазмов в примерах (37-38) ответ напрашивается сам собой: императивный предикат здесь является темой. В частности, в первом из этих примеров, 'отделение и расплющивание' является частью ремы в первой клаузе, что и обеспечивает статус прагматической пресуппозиции для того же концепта в следующей клаузе, где рема, напротив, состоит из актантов. Как обычно бывает в клаузах без выделенного фокуса, рема (comment) в наших примерах следует за темой (topic). Относительно необычным здесь является лишь то, что в качестве темы во второй клаузе выступает предикат.

От хиазмов в обсуждаемых текстах следует отличать псевдо-хиазмы, когда клауза SOV в хеттском описании ритуала контрастирует со сходной клаузой VSO в лувийском заклинании. Так обстоят дела в примерах (39) и (40), где приводятся в более широком контексте пролептические конструкции из примеров (16) и (27) соответственно. После того, как заказчик ритуала совершает определенное обрядовое действие, исполнительница ритуала интерпретирует данный акт в общепринятых магических терминах. C ее точки зрения, последнее действие заказчика ритуала является новым ситуативным фокусом, а сам заказчик и абстрактные негативные сущности, такие как 'проклятие' или 'злой язык' - освоенными референтами, не относя- 
щимися к фокусу ситуации. В конструкциях с выделенным фокусом, компонент в фокусе часто предшествует другим компонентами информационной структуры, ср. синтаксис русских предложений с фокусными частицами именно, только или даже. Опять-таки, относительно необычным является лишь вынесение предиката в фокусную позицию.

(39) KUB 32.9+ rev. 28'-31' (CTH 760)

$\mathrm{nu}=\mathrm{za}=\mathrm{kan} \quad B E L \quad$ SÍS[KUR $Q \bar{A} T I=\check{S} U]$ ārri $\mathrm{n}[\mathrm{u}]{ }^{\left.\mathrm{M}_{[} \mathrm{UNUS} \check{S} U . G I\right]}$ kiššan [tezzi] ililhāi=ti ma[1]haššaššiš [EN-aš] taparu dāta[riyamman] hirūn

'Заказчик рит[уала] моет [руки]. Ис[полнительница ритуала говорит] таким образом: “(Вот) смывает с себя [заказчик] ри[т]уала [на]пасть, про[клятие], (и) (лживую) клятву." '

(40) KBo 29.3+ iii 13'-14', 16'-17' (CTH 761)

[nu EN SÍSKUR] iš[naš EME-uš iš]našš=a kiššaruš [arha

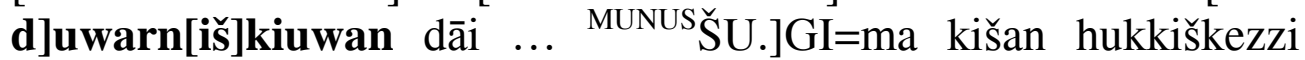
$\mathbf{m a}[\mathbf{m}] \mathbf{m a l w a y}=$ an EN SÍSKUR-iš adduwalin EME-in

'[Заказчик ритуала] начинает [раз]лам[ыв]ать [языки из] те[ста] и руки из [те]ста. ... А [исполнительница] ритуала заклинает таким образом: “(Вот) сок[р]ушет его заказчик ритуала, злой язык..." '.

Вариантом данной ситуации является положение дел, когда исполнитель(ница) ритуала комментирует не само обрядовое действие, а его желаемый результат. В этом случае лувийское заклинание открывается императивной клаузой, в которой, однако, предикат или предикативная группа также находятся в начальной позиции. Так, например, клауза (1) из настоящей статьи, 'Пусть будут омыты $\|$ [дре]весина, земля, х.-ы [бог]ов (и) алта(рь)!', произносится в качестве заклинания после того, как исполнитель ритуала передает заказчику сосуд с водой. Здесь можно видеть конструкцию с сентенциальным фокусом, прагматической конфигурацией, которая характеризуется отсутствием составляющих в пресуппозиции (Lambrecht, Polinsky 1997: 2). Одной из типичных стратегий кодирования сентенциального фокуса в языках с тенденцией к конечной позиции предиката является порядок слов $\mathrm{V}_{1}$ (Lambrecht 2000: 634-635), что мы и наблюдаем в обсуждаемом примере. Представляется, что подобный анализ также является оптимальным и для 
нескольких других случаев императивных клауз в начале лувийских заклинаний. ${ }^{16}$

Однако наиболее удачной иллюстрацией сентенциального фокуса являются конструкции (9-12), также располагающиеся в начале заклинаний и вводимые частицей zawi 'вот'. Эти клаузы используются для презентации различных ритуальных объектов, что хорошо согласуется с наблюдением о базовой функции презентации для данной прагматической конфигурации (Lambrecht 2000: 623). Здесь мы также имеем дело с последовательным порядком слов $\mathrm{V}_{1}$, хотя его формальное описание в терминах выноса влево или выноса вправо представляется одинаково вероятным. Как мы видели выше в Разделе 3, на местоименную репризу внутри данной группы наложены дополнительные ограничения, что делает в принципе невозможным анализ лувийской пролептической конструкции как функции одного параметра.

В заключение хотелось бы отметить, что наличие различных прагматических конфигураций, соотносимых с выносом влево в лувийском, ни в коей мере не должно восприниматься как доказательство правильности представленного синтаксического анализа. Формальные причины, по которым удобно разделять синхронные случаи выноса влево и выноса вправо были представлены в Разделе 4, а сравнительные данные ликийского языка, подтверждающие наличие механизма выноса влево в истории лувических языков, обсуждались в Разделе 2. Описание коммуникативной структуры лувийских текстов не требует само по себе отсылок к синтаксическим трансформациям (ср. Раздел 1). В то же время, для апробации нашей гипотезы важно то, что результаты сравнительно-исторического, синтаксического и прагматического анализа оказываются принципиально совместимыми.

\footnotetext{
${ }^{16}$ При этом важно подчеркнуть, что предикат в начальной позиции может являться сложной глагольной формой, как в примере (1), или даже глагольной группой с легким (семантически слабым) глаголом. Последняя интерпретация возможна, например, для заклинания (34), которое следует в ритуале за актом сожжения символа злонамеренного волшебства над сосудом с маслом и медом. Это предложение интересно еще и тем, что в предыдущем разделе оно разбиралось как пример выноса вправо громоздкой группы подлежащего. Два объяснения - чисто синтаксическое и прагматическое - в данном случае дополняют друг друга.
} 


\section{Литература}

Adiego, I.-X. 2015: Lycian Nasalized Preterites Revisited. Indogermanische Forschungen 120/1, 1-30.

Garrett, A. 1991: The Lycian Nasalized Preterite. Münchener Studien für Sprachwissenschaft 52, 15-26.

Garrett, A. 1994: Relative Clause Syntax in Lycian and Hittite. Die Sprache 36, 29-69.

Goldstein, D. 2014: Object Agreement in Lycian. Historische Sprachforschung 127, 101-124.

Görke, S. 2010: Das Ritual der Aštu (CTH 490). Culture and History of Ancient Near East 40. Leiden: Brill.

Kalluli, D., Tasmowski L. 2008: Introduction: Clitic doubling, core syntax and the interfaces. Dalina Kalluli and Liliane Tasmowski (eds.), Clitic Doubling in the Balkan Languages. Amsterdam: John Benjamins, 1-32.

Hawkins, J. D. 2000: Corpus of Hieroglyphic Luwian Inscriptions. Vol. I. Part I, II: Texts; Part III: Plates. Untersuchungen zur indogermanischen Sprach- und Kulturwissenschaft NF 8. Berlin: de Gruyter.

Melchert, H. C. 2003: Language. The Luwians, H. Craig Melchert, (ed.). Handbuch der Orientalistik I/68. Leiden: Brill, 170-210.

Melchert, H. C. 2006: Indo-European Verbal Art in Luvian. La langue poétique indo-européenne: Actes du Colloque de travail de la Société des Études Indo-Européennes, Paris, 22-24 octobre 2003. Ed. George-Jean Pinault and Daniel Petit (eds). Leuven: Peeters, 291-298.

Melchert, H. C. 2015: Alleged "Right Dislocation" in Hittite. Saeculum: Gedenkschrift für Heinrich Otten anlässlich seines 100. Geburtstags. Andreas Müller-Karpe et al. (eds). Wiesbaden: Harrassowitz, 137-145.

Molina, M. A. 2019: Poryadok slov v hettskom yazyke [Word order in Hittite: corpus methods and analysis in typological perspective]. $\mathrm{PhD}$ dissertation. Moscow.

Молина, М. А. 2019: Порядок слов в хеттском языке: корпусные методы и анализ в типологической перспективе. Дис. на соискание ученой степени кандидата филологических наук. М.

Lambrecht, K. 1994. Information Structure and Sentence Form. Cambridge: Cambridge University Press.

Lambrecht, K. 2000. When subjects behave like objects: The analysis of the merging of $\mathrm{S}$ and $\mathrm{O}$ in sentence-focus constructions across languages. Studies in Language 24/3, 611-682.

Lambrecht, K., Polinsky, M. 1997: Typological Variation in SentenceFocus Constructions. Proceedings of the Thirty-third Annual Meeting of the Chicago Linguistic Society. Papers from the Panels. Kora Singer et al. (eds.), 189-206. Chicago: Chicago Linguistic Society, 1-21. 
Lopashov, Ju. A. 1978: Mestoimennye povtory dopolneniya $v$ balkanskikh yazykakh [The pronominal reiteration of the object in Balkan languages]. Leningrad: Nauka.

Лопашов, Ю. А. 1978: Местоименные повторы дополнения в балканских языках. Л.: Наука.

Mouton, A., Yakubovich, I. 2019: Internal or external evil: a merism in Luwian incantations. Bulletin of SOAS 82/2: 209-231.

Prince, E. F. 1981: Toward a Taxonomy of Given-New Information. Radical Pragmatics. Peter Cole (ed.). New York: Academic Press, 223-255.

Rieken, E. 2008: Die Zeichen <ta>, <tá> und <tà > in den hieroglyphenluwischen Inschriften der Nachgroßreichszeit, VI Congresso Internazionale di Ittitologia, (Roma 5-9 settembre 2005). A. Archi und R. Francia (eds). Studi micenei ed egeo-anatolici 50, 637-649.

Rieken, E. 2011: Verberststellung in hethitischen Übersetzungstexten. Indogermanistik und Linguistik im Dialog: Akten der XIII. Fachtagung der Indogermanischen Gesellschaft vom 21. bis 27. September 2008 in Salzburg. Thomas Krisch and Thomas Lindner (eds). Wiesbaden: Reichert, 498-507.

Rieken, E., Yakubovich, I. Forthcoming. Hidden Pronominal Clitics in Luwian Texts. To appear in a forthcoming Festschrift.

Rizza, A. 2007: I pronomi enclitici nei testi etei di traduzione dal Hattico. Studia Mediterranea 20. Pavia: Italian University Press.

Shevoroshkin, V. V. 2012: [Chiasm and similar structures in the Milyan texts]. Armyanskiy gumanitarny vestnik [Armenian Humanitarian Journal] 4, 98-120.

Шеворошкин, В. В. 2012: Хиазмы и сходные структуры в милийских текстах. Армянский гуманитарный вестник 4, 98-120.

Sideltsev, A. 2002: Inverted word order in Middle Hittite. Anatolian Languages. Vitaly V. Shevoroshkin and Paul Sidwell (eds). Canberra: Association for the History of Language,. 138-188.

Sideltsev, A. 2011: Clitic Doubling: A new Syntactic Category in Hittite. Altorientalische Forschungen 38/1, 81-91.

Sideltsev, A. 2012: [Right dislocations with pronominal reduplication in Cuneiform Luwian]. Indoevropeyskoe yazykoznanie $i$ klassicheskaya filologiya [Indo-European linguistics and classical philology] 16: 772-784.

Сидельцев, А. В. 2012: Выносы вправо с местоименной репризой в лувийском. Индоевропейское языкознание и классическая филология 16: 772-784.

Starke, F. 1985. Die keilschrift-luwischen Texte in Umschrift. Studien zu den Bogazköy-Texten 30. Wiesbaden: Harrassowitz.

Wratil, M. 2010: The Development of the V-to-C Movement in the West Germanic and Romance Languages. Diachronic Studies on Information Structure: Language Acquisition and Change. Gisella Ferraresi and Rosemarie Lühr (eds.). Berlin: Mouton, 161-188. 
Yakubovich, I. 2012. The Reading of Luwian ARHA and Related Problems. Altorientalische Forschungen 39/2 (2012), 321-39.

Yakubovich, I. 2015: Phoenician and Luwian in Early Iron Age Cilicia. Anatolian Studies 65, 35-53.

Yakubovich, I. 2019: Luviyskiy yazyk v prostranstve i vremeni [The Luwian Language in Space and Time]. Moscow: YaSK.

Якубович, И. С. 2019: Лувийский язык в пространстве и времени. М.: ЯСК. 